\title{
Monitoring of Ground Deformation due to Excessive Withdrawal of Natural Gas Using SBAS
}

\author{
Bo Hu \\ State Key Laboratory of Geodesy and Earth's Dynamics, Institute of Geodesy and Geophysics, \\ Chinese Academy of Sciences, Wuhan 430077, China \\ Correspondence should be addressed to Bo Hu; hubo@asch.whigg.ac.cn
}

Received 6 May 2014; Revised 22 July 2014; Accepted 5 August 2014; Published 27 August 2014

Academic Editor: Qingsong Xu

Copyright (C) 2014 Bo Hu. This is an open access article distributed under the Creative Commons Attribution License, which permits unrestricted use, distribution, and reproduction in any medium, provided the original work is properly cited.

\begin{abstract}
The excessive withdrawal of natural gas can generate a wide range of ground deformation. The aim of this paper is to investigate ground deformation in Chiba Prefecture, Japan, using the Small Baseline Subset (SBAS) technique. In recent years, the local government has taken a series of measures such as artificial recharge and reduction of groundwater withdrawal to alleviate the ground settlement. In order to more fully investigate the spatial and temporal variation of deformation that occurred in Chiba Prefecture, we process a dataset of 34 ASAR images acquired from September 2006 to August 2010 based on SBAS technique and generate the mean deformation velocity map and time series deformation maps. The results show that (1) a relatively stable in Mao Yuan area, with an average subsidence velocity of $-0.91 \mathrm{~mm} / \mathrm{y}$. (2) large uplift rates were highlighted in albino Ding and Kujukuri, which average deformation velocity were about $5.11 \mathrm{~mm} / \mathrm{y}$ and $6.15 \mathrm{~mm} / \mathrm{y}$ respectively.
\end{abstract}

\section{Introduction}

Various crustal movements and anthropogenic activities can result in ground deformation. Crustal movements can result from landslides, earthquakes, volcanic activity, glacial rebound, and subsidence. Anthropogenic causes of displacements include underground resources exploitation [1-5]. However, accurate detection of small deformation over large areas was very difficult in the past. In this background, Multitemporal InSAR has emerged as an effective technique to detect surface displacements with millimeter accuracy. Advanced InSAR technique known as Small Baseline Subset (SBAS) approach has been developed to analyze the temporal evolution of the deformation through the generation of time series of ground displacements [6-10].

The formation of Kanto Plain around Tokyo Bay, Japan, is sediment in the oceanic environment through several hundred thousand years or even million years of geological activity. Under this geological activity, Ocean Plankton was transformed into high quality water soluble natural gas [11]. Since the 1930s, there were gas production activities near Tokyo. Large-scale production of gas in Chiba Prefecture area started from 1960. Production was conducted through withdrawal of groundwater from the depth of 500 to $2000 \mathrm{~m}$. Land subsidence was found since the 1960s and large-scale land subsidence surveying was started in 1969. During the past 35 years, the maximum accumulated subsidence was $0.85 \mathrm{~m}$ and subsided area was $800 \mathrm{~km}^{2}$ [12]. The coastal line of Chiba Prefecture backed off $30-60 \mathrm{~m}$ from its position in the 1960s. In 2005, there is about $15 \mathrm{~mm}$ subsidence per year yet. From 2006 to 2010, the local government had taken recharge groundwater to alleviate the settlement. The previously subsidence area had been alleviated, or even uplift [13]. Therefore, accurate detecting and time-series analysis of subsidence change in water-soluble natural gas mining areas, together with the analysis of its driving force, are critically needed for the early hazard warning and sustainable mining.

\section{Description of Study Area and Data Sets}

Chiba Prefecture borders Ibaraki Prefecture to the north at the Tone River, Tokyo, and Saitama Prefecture to the west at the Edo River, the Pacific Ocean to the east and Tokyo Bay around its southern boundary. The geographic extent of Chiba Prefecture is marked by longitudes $140^{\circ} 13^{\prime} \mathrm{E}-114^{\circ} 26^{\prime} \mathrm{E}$ 
TABLE 1: Acquisition date of ASAR C-band ASAR data (descending, track: 489) used in this study.

\begin{tabular}{|c|c|}
\hline Number & Acquisition date \\
\hline 1 & $2006 / 09 / 04$ \\
\hline 2 & 2006/10/09 \\
\hline 3 & $2006 / 11 / 13$ \\
\hline 4 & $2006 / 12 / 18$ \\
\hline 5 & $2007 / 01 / 22$ \\
\hline 6 & $2007 / 05 / 07$ \\
\hline 7 & 2007/06/11 \\
\hline 8 & $2007 / 07 / 16$ \\
\hline 9 & $2007 / 08 / 20$ \\
\hline 10 & $2007 / 09 / 24$ \\
\hline 11 & $2007 / 10 / 29$ \\
\hline 12 & $2007 / 12 / 03$ \\
\hline 13 & $2008 / 01 / 07$ \\
\hline 14 & $2008 / 02 / 11$ \\
\hline 15 & $2008 / 03 / 17$ \\
\hline 16 & $2008 / 04 / 21$ \\
\hline 17 & $2008 / 05 / 26$ \\
\hline 18 & $2008 / 06 / 30$ \\
\hline 19 & $2008 / 08 / 04$ \\
\hline 20 & 2008/09/08 \\
\hline 21 & $2008 / 10 / 13$ \\
\hline 22 & 2008/11/17 \\
\hline 23 & $2008 / 12 / 22$ \\
\hline 24 & 2009/03/02 \\
\hline 25 & 2009/05/11 \\
\hline 26 & $2009 / 07 / 20$ \\
\hline 27 & $2009 / 09 / 28$ \\
\hline 28 & $2009 / 12 / 07$ \\
\hline 29 & $2010 / 02 / 15$ \\
\hline 30 & $2010 / 03 / 22$ \\
\hline 31 & $2010 / 04 / 26$ \\
\hline 32 & $2010 / 05 / 31$ \\
\hline 33 & 2010/07/05 \\
\hline 34 & 2010/08/09 \\
\hline
\end{tabular}

and latitudes $35^{\circ} 22^{\prime} \mathrm{N}-35^{\circ} 30^{\prime} \mathrm{N}$ with a total area of around $269.8 \mathrm{~km}^{2}$. Most of Chiba lies on the hilly Boso Peninsula, a rice farming region: the east coast, known as the Kujükuri Plain, is an especially productive area. The most populous zone, in the northwest of the prefecture, is part of the Kantō region that extends into the urban agglomeration of Tokyo and Saitama [13], the study area shown in Figure 1.

In this study, the ASAR dataset over the Chiba Prefecture area contains 34 descending acquisitions in IS2 acquisition mode and VV polarization. The temporal coverage is from 2006-09-04 till 2010-08-09 (see Table 1).

Besides the SAR data, an accurate digital elevation model (DEM), in an ellipsoidal reference system, is prepared before processing the SAR data. If a better DEM is not available, you can use free SRTM [14]. The ASAR scene acquired on Jue. 30, 2008, was used as the super master image. The super

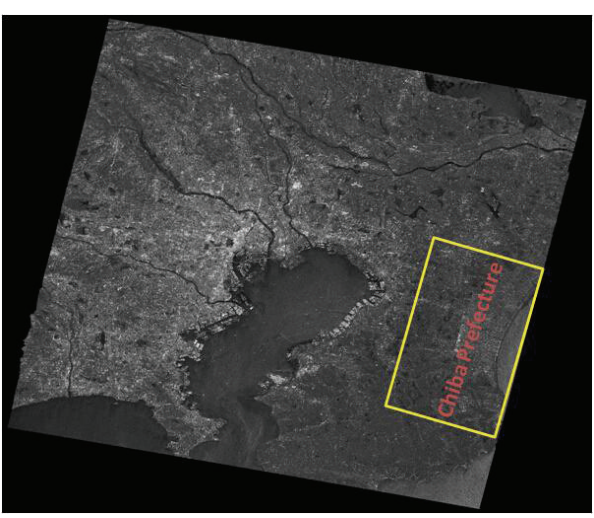

FIGURE 1: The yellow square overlaid on the ASAR intensity map outline of the study area.

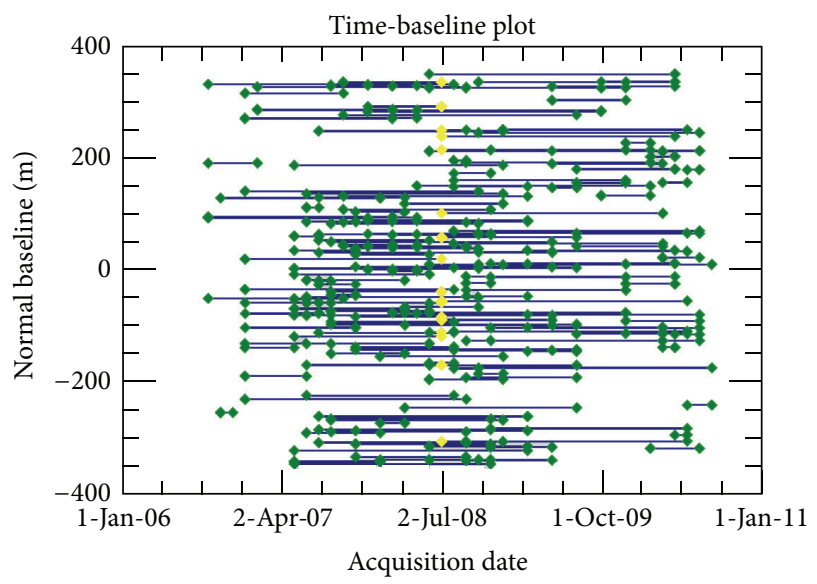

FIgURE 2: Time-baseline plots relevant to the ASAR images and interferograms used in this study. The green points represent the ASAR acquisition dates. The yellow point represents the super master image acquisition date.

master is the reference image of the whole processing, and all the processed slant range pairs will be coregistered on this reference geometry.

Given $N$ acquisitions, the maximum theoretical available interferograms are $(N *(N-1)) / 2$. From the whole set of interferograms formed by all possible pairs of images, only those with a perpendicular component of spatial baseline smaller than $350 \mathrm{~m}$, a temporal baseline shorter than 180 days, and a relative Doppler centroid difference below $991 \mathrm{~Hz}$ were selected for the following interferometric analysis. By limiting the baselines, the most incoherent interferograms were rejected; the number of all generated interferograms is 213. The temporal baselines of these selected interferograms are shown in Figure 2. From the 213 selected interferograms, 108 interferograms having temporal baselines lower than 180 days and perpendicular baselines less than $100 \mathrm{~m}$ were considered as the most significant in terms of the description of the deformation and therefore were stacked (see Figure 3). Spatial phase unwrapping was carried out prior to the stacking analysis. It was accomplished in this work using 


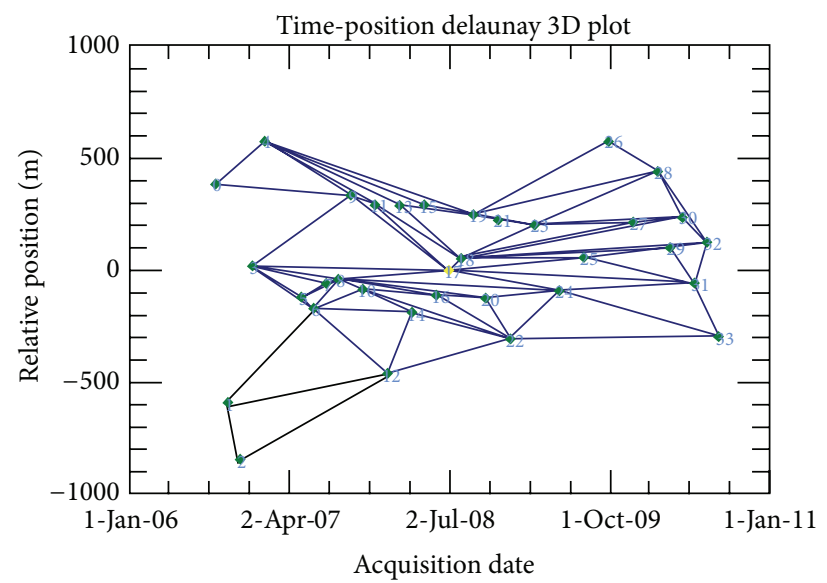

FIGURE 3: Subset of the whole interferograms that will be unwrapped in 3D. The blue points represent the ASAR acquisition dates. The yellow point represents the super master image acquisition date.

the MCF phase unwrapping algorithm applied to a triangular irregular network.

\section{Principles and Process Flow of the SBAS}

SBAS technique was proposed by Berardino et al. in 2002 [7]. This technique is based on the combination of differential interferograms, which is a postprocessing method to generate the mean deformation velocity maps and displacement time series. A detailed discussion on the SBAS algorithm can be referenced in [8].

Assuming the existence of $N$ SAR images, the imaging time was $t_{0}, \ldots t_{N-1}$. According to the vertical baseline threshold, the above images are grouped. Images within each grouped performs differential interferometric processing, the number of the resulting interferogram $K$ met:

$$
\frac{N}{2} \leq K \leq N\left(\frac{N-1}{2}\right) \text {. }
$$

For a point $(x, r)$ on the $j$ th interferograms, the deformation phases of the two images $t_{A}$ and $t_{B}$ were acquired after removing the topographic phase:

$$
\begin{aligned}
\delta \phi_{j}(x, r) & =\phi\left(t_{B}, x, r\right)-\phi\left(t_{A}, x, r\right) \\
\approx & \frac{4 \pi}{\lambda}\left[d\left(t_{B}, x, r\right)-d\left(t_{B}, x, r\right)\right], \\
& j=0, \ldots, N-1,
\end{aligned}
$$

where $d\left(t_{B}, x, r\right)$ and $d\left(t_{A}, x, r\right)$ are the radar line of sight projections of the cumulative deformation at $t_{B}$ and $t_{A}$ with respect to the first scene $t_{0}$ assumed as a reference.

Equation (2) allows us to define a system of $M$ equations in the $N$ unknowns $\phi\left(t_{i}, x, r\right)$, which can be reorganized, by using matrix formalism, as follows:

$$
A \phi=\delta \phi,
$$

where $A$ is an incidence-like matrix directly related to the set of interferograms generated from the available data.
Accordingly, the dependence on the variables $(x, r)$ has been neglected in (3) and this simplification will be maintained hereafter in the overall matrix representation.

We may now manipulate the system of (3) in such a way to replace the present unknowns with the mean phase velocity between time adjacent acquisitions. Accordingly, the new unknowns become

$v=\left[v_{1}=\frac{\phi\left(t_{1}, x, r\right)}{t_{1}-t_{0}}, \ldots, v_{N}=\frac{\phi\left(t_{N}, x, r\right)-\phi\left(t_{N-1}, x, r\right)}{t_{N}-t_{N-1}}\right]$.

And by substituting (4) in (3), we finally get the new equation:

$$
B v=\delta \phi
$$

where $B$ is an $M \times N$ matrix corresponding to the unknown vector. In the end, the singular value decomposition (SVD) is applied; you can get the deformation velocity of each time period. At the same time, a filtering step is carried out to remove the atmospheric phase artifacts (APS) and orbital ramps [14-17]. In order to intuitively understand the SBAS, the basic flow of the SBAS is depicted in Figure 4.

\section{Results and Interpretation}

The following section presents results that have been achieved based on SBAS technique. The results are based on processing 34 ASAR data (see Table 1). In the process of obtaining differential interferograms, we conducted 1:5 multilook in the distance and azimuth direction, respectively, so each pixel size is about $20 \mathrm{~m} \times 20 \mathrm{~m}$. The average surface displacement velocity is shown in Figure 5. The negative sign stands for subsidence, whereas the positive sign is uplift. It can be observed that several significant uplift areas are detected in the natural gas field area, which is shown in Figure 5 by superimposed on the SAR intensity image. It is clear that many ground subsidence funnels have been found around the gas field, in which the maximum subsidence velocity 


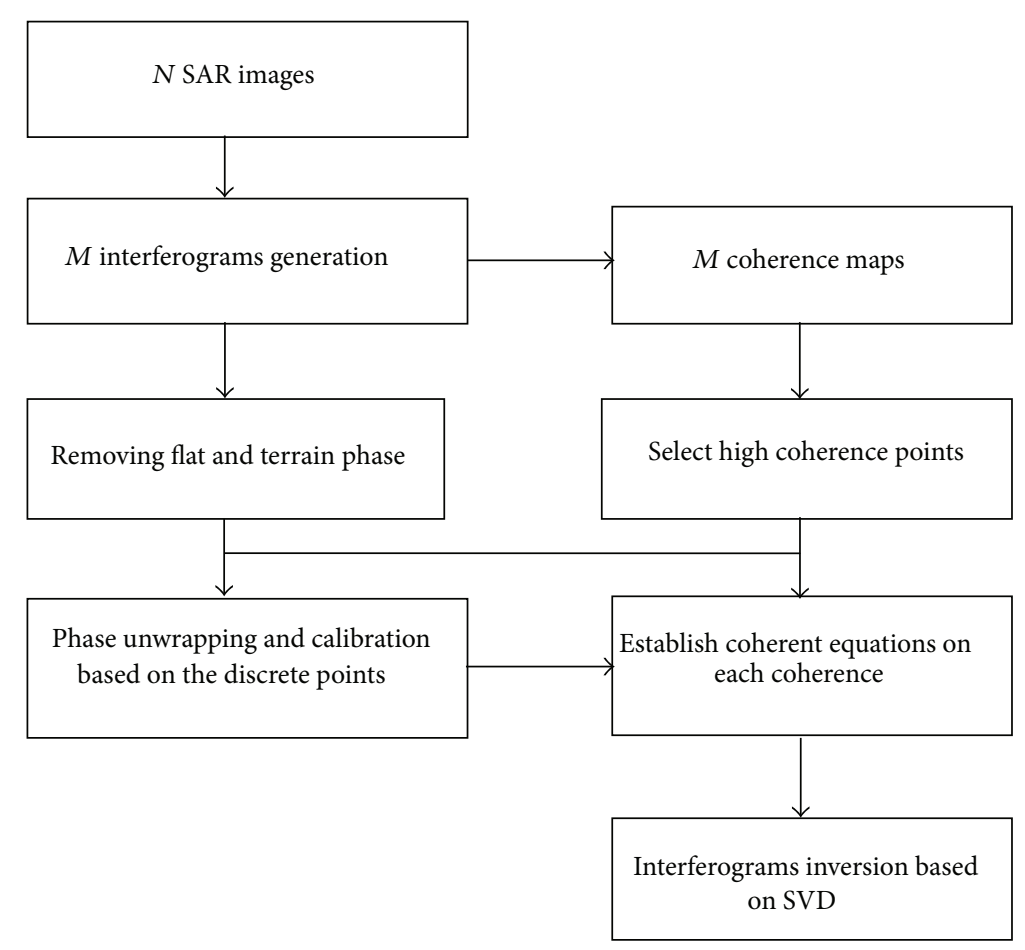

Figure 4: Basic flow of the SBAS.

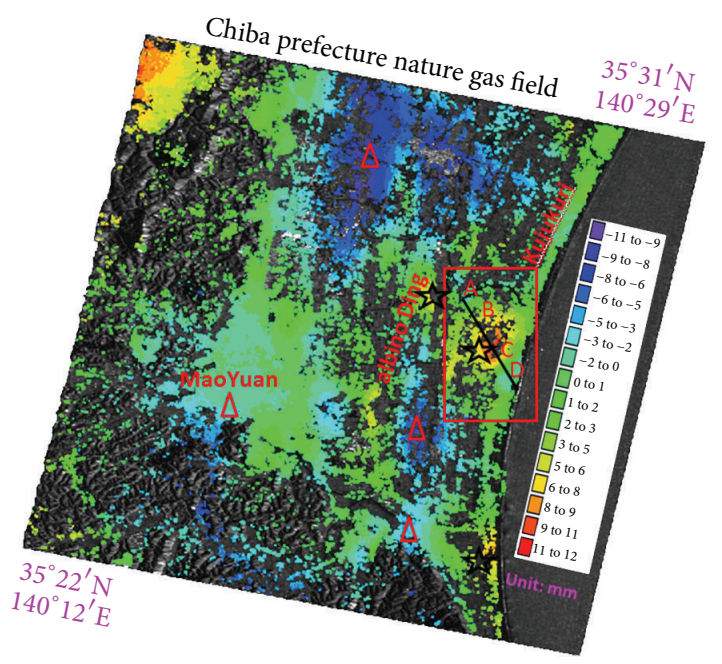

FIGURE 5: Mean velocity estimate using the SBAS technique. Black line is a hatch through gas field area, and A, B, C, and D are the feature points in the hatch. Red box indicates the area amplified in Figure 7. Red triangles represent the location of groundwater wells; black pentagrams represent the location where the water is injected.

exceeds $-11 \mathrm{~mm} /$ year in the LOS direction. In the meantime, some uplift areas have been found around some natural gas field after recharge, in which the maximum uplift velocity exceeds $12 \mathrm{~mm} /$ year in the LOS direction. According to the filed investigation, these regions are all in or close to the natural gas mining areas. The results showed a relatively stable pattern in Mao Yuan, with an average subsidence velocity of $-0.91 \mathrm{~mm} /$ year. In contrast, relatively large uplift rates were highlighted in albino Ding and Kujukuri, in which average subsidence velocity was about $5.11 \mathrm{~mm} /$ year and $6.15 \mathrm{~mm} /$ year, respectively. Additionally, the local government has been taking recharge to alleviate the settlement since 2000. Therefore, we can infer that these land subsidence are induced by the natural gas mining in the underground and ground uplift are induced by water injection from 2006 to 2010 .

In order to investigate the development of the ground displacements caused by gas extraction and water injection in Chiba Prefecture, the area located in the gas field, where the location is confined by the box in Figure 5, is chosen to exhibit the time series of surface deformation resulting from the SBAS algorithm. As shown in Figure 6, each subplot represents the surface deformation during the period of Sep. 4, 2006, and the date plot in the upper left corner of the subplot. The black region indicates the mask area with low correlation. It is clear that a rebound center has been expanding in scale and aggravating in quantity during about 4 years. The largest rebound occurred in the center of the gas field after water injection for the value of more than $30 \mathrm{~mm}$ in the LOS direction since the year of 2006. Besides, a moderate ground rebound is found below the gas field. In addition, in order to intuitively analyze the deformation of the gas field area, the black hatch deformation is shown in Figure 7 and the time series deformation of the feature points is shown in Figure 8. From the time series deformation we can find the ground rebound with the increase of the amount of recharge after the year of 2006 . 


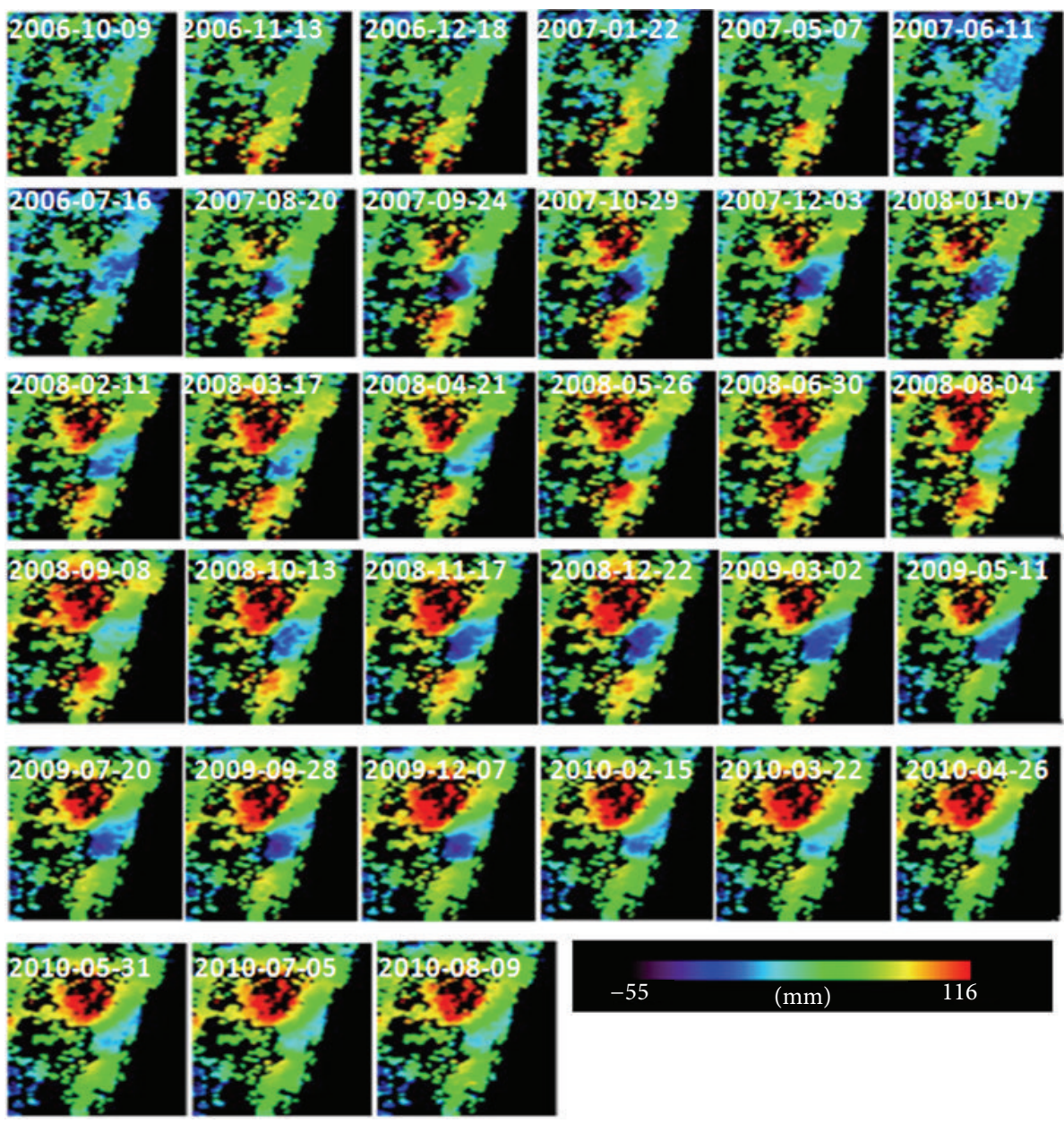

Figure 6: The time series surface deformations at the 33 considered dates with respect to Sep. 4, 2006.

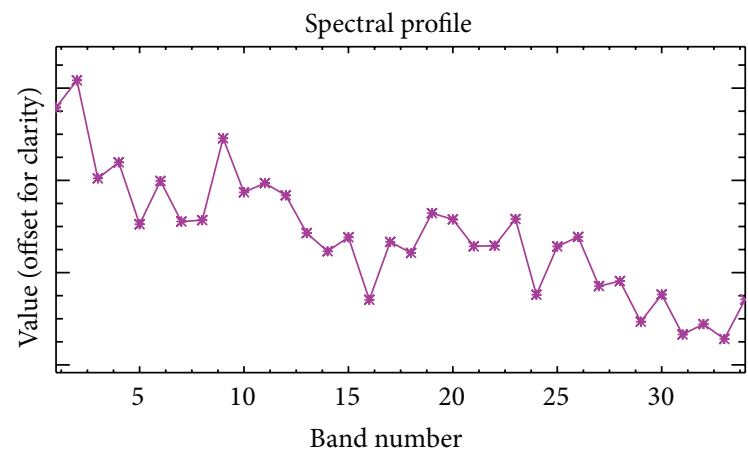

FIGURE 7: The black hatch deformations at Aug. 9, 2010.

\section{Conclusions}

In this paper, we exploited SBAS technique to investigate the land deformation in LOS direction due to withdrawal of water-soluble natural gas in Chiba Prefecture (Japan) with 34 ASAR data between Sep. 4, 2006, and Aug. 9, 2010. The result in our paper reveals that the area of nature gas mining in Chiba Prefecture has experienced great ground rebound in nearly 4 years, where the maximum accumulation exceeds

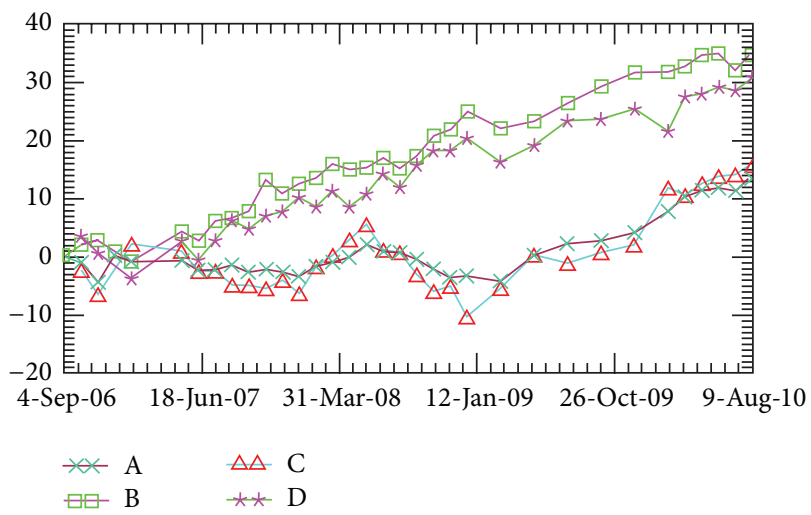

Figure 8: The time series surface deformations at the 4 feature points (A, B, C, and D) along the hatch with respect to Sep. 4, 2006.

$30 \mathrm{~mm}$. The presentation of result has much significance to the precaution of gas mining geologic hazard and environment disruption. Due to lack of the ground survey data, we cannot accurately compare the SBAS results currently, but next step is to collect detailed compared ground survey data, for example, leveling, GPS. 


\section{Conflict of Interests}

The author declares that there is no conflict of interests regarding the publication of this paper.

\section{Acknowledgments}

This work was supported by the CRSRI Open Research Program (CKWV2013211/KY), National Natural Science Foundation of China (Grant nos. 41204012, 41431070, 41021003, 41274026, 41174016, 41274024, and 41474014), CAS/SAFEA International Partnership Program for Creative Research Teams (Grant no. KZZD-EW-TZ-05), Opening Fund of SKLGED Laboratory (SKLGED2013-7-2-Z, SKLGED2013-73-Z, SKLGED2014-5-3-E), Hunan Province Key Laboratory of Coal Resources Clean-Utilization and Mine Environment Protection (E21419). The author thanks the European Space Agency, which has provided ASAR data relevant to the Chiba Prefecture (Japan) area within the Cat-1/13012, and the ESRI for the ENVI/SARscape software. Finally, the author wishes to acknowledge the helpful comments of the reviewers and editor.

\section{References}

[1] F. Guzzetti, M. Manunta, F. Ardizzone et al., "Analysis of ground deformation detected using the SBAS-DInSAR technique in Umbria, Central Italy," Pure and Applied Geophysics, vol. 166, no. 8-9, pp. 1425-1459, 2009.

[2] J. Baek, S.-W. Kim, H.-J. Park, H.-S. Jung, K.-D. Kim, and J. W. Kim, "Analysis of ground subsidence in coal mining area using SAR interferometry," Geosciences Journal, vol. 12, no. 3, pp. 277284, 2008.

[3] J. K. Hole, C. J. Bromley, N. F. Stevens, and G. Wadge, "Subsidence in the geothermal fields of the Taupo Volcanic Zone, New Zealand from 1996 to 2005 measured by InSAR," Journal of Volcanology and Geothermal Research, vol. 166, no. 3-4, pp. 125-146, 2007.

[4] Y. Yan, M. P. Doin, P. López-Quiroz et al., "Mexico city subsidence measured by InSAR time series: joint analysis using PS and SBAS approaches," IEEE Journal of Selected Topics in Applied Earth Observations and Remote Sensing, vol. 5, no. 4, pp. 1312-1326, 2012.

[5] B. Hu, H. Wang, and L. Jiang, "Monitoring of the reclamationinduced ground subsidence in Macao (China) using the PSInSAR technique," Journal of Central South University, vol. 20, no. 4, pp. 1039-1046, 2013.

[6] A. K. Gabriel, R. M. Goldstein, and H. A. Zebker, "Mapping small elevation changes over large areas: differential radar interferometry," Journal of Geophysical Research, vol. 94, no. 7, pp. 9183-9191, 1989.

[7] P. Berardino, G. Fornaro, R. Lanari, and E. Sansosti, "A new algorithm for surface deformation monitoring based on small baseline differential SAR interferograms," IEEE Transactions on Geoscience and Remote Sensing, vol. 40, no. 11, pp. 2375-2383, 2002.

[8] R. Lanari, O. Mora, M. Manunta, J. J. Mallorquí, P. Berardino, and E. Sansosti, "A small-baseline approach for investigating deformations on full-resolution differential SAR interferograms," IEEE Transactions on Geoscience and Remote Sensing, vol. 42, no. 7, pp. 1377-1386, 2004.
[9] A. H. Ng, L. Ge, X. Li, H. Z. Abidin, H. Andreas, and K. Zhang, "Mapping land subsidence in Jakarta, Indonesia using persistent scatterer interferometry (PSI) technique with ALOS PALSAR," International Journal of Applied Earth Observation and Geoinformation, vol. 18, no. 1, pp. 232-242, 2012.

[10] R. Lanari, P. Lundgren, M. Manzo, and F. Casu, "Satellite radar interferometry time series analysis of surface deformation for Los Angeles, California," Geophysical Research Letters, vol. 31, Article ID L23613, pp. 1-5, 2004.

[11] S. Shen, Y. Xu, and T. Ikuo, "Land subsidence due to withdrawal of water soluble natural gas from deep marine sediments," Chinese Journal of Rock Mechanics and Engineering, vol. 24, no. 6, pp. 1094-1098, 2006.

[12] S. Shen, Y. Xu, and I. Tohno, "Land subsidence due to withdrawal of water soluble natural gas from deep marine sediments," Chinese Journal of Rock Mechanics and Engineering, vol. 25, no. 2, pp. 5389-5394, 2006.

[13] http://en.wikipedia.org/wiki/Chiba_Prefecture.

[14] B. Hu, H.-S. Wang, Y.-L. Sun, J.-G. Hou, and J. Liang, "Longterm land subsidence monitoring of Beijing (China) using the Small Baseline Subset (SBAS) technique," Remote Sensing, vol. 6, pp. 3648-3661, 2014.

[15] G. W. Bawden, W. Thatcher, R. S. Stein, K. W. Hudnut, and G. Peltzer, "Tectonic contraction across Los Angeles after removal of groundwater pumping effects," Nature, vol. 412, no. 6849, pp. 812-815, 2001.

[16] S. Usai, "A least squares database approach for SAR interferometric data," IEEE Transactions on Geoscience and Remote Sensing, vol. 41, no. 4, pp. 753-760, 2003.

[17] S. C. Dong, S. Samsonov, S. J. Yin, and Y. R. Cao, “Timeseries analysis of subsidence associated with rapid urbanization in Shanghai, China measured with SBAS InSAR method," Enviromental Earth Sciences, vol. 72, no. 3, pp. 677-691, 2014. 


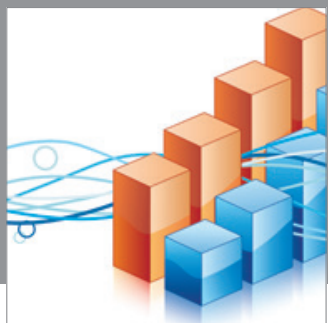

Advances in

Operations Research

mansans

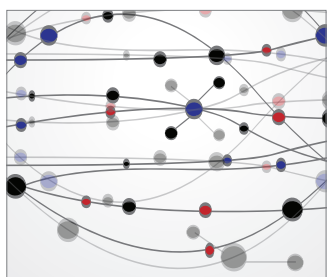

The Scientific World Journal
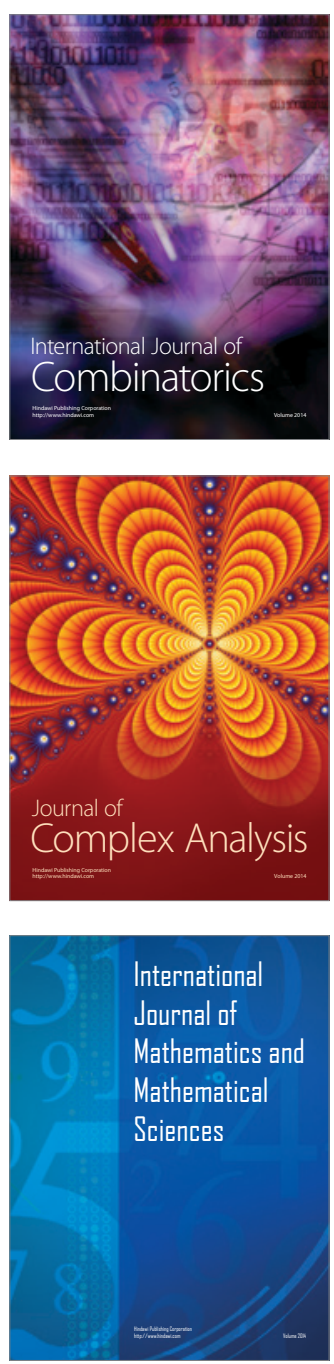
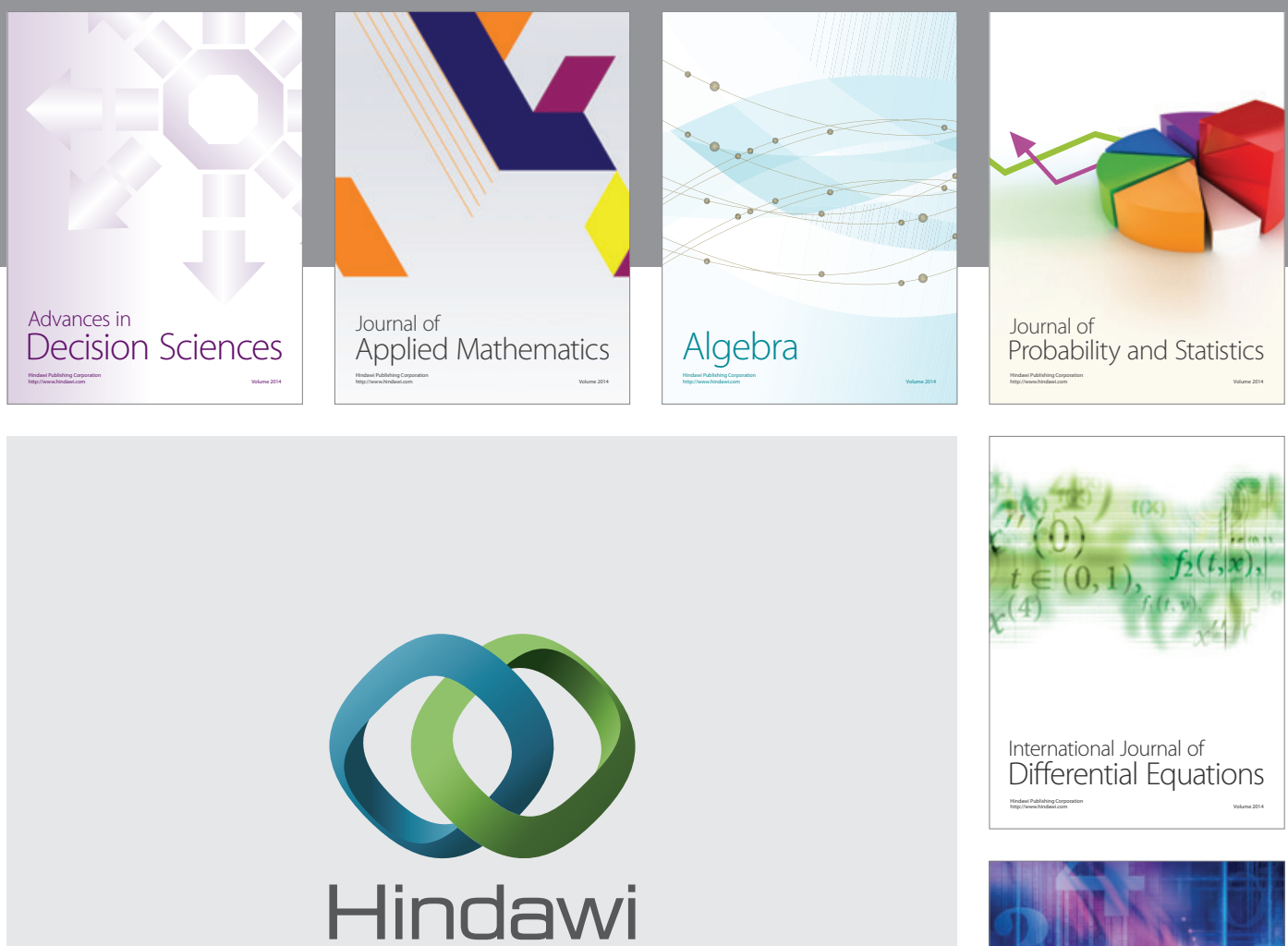

Submit your manuscripts at http://www.hindawi.com
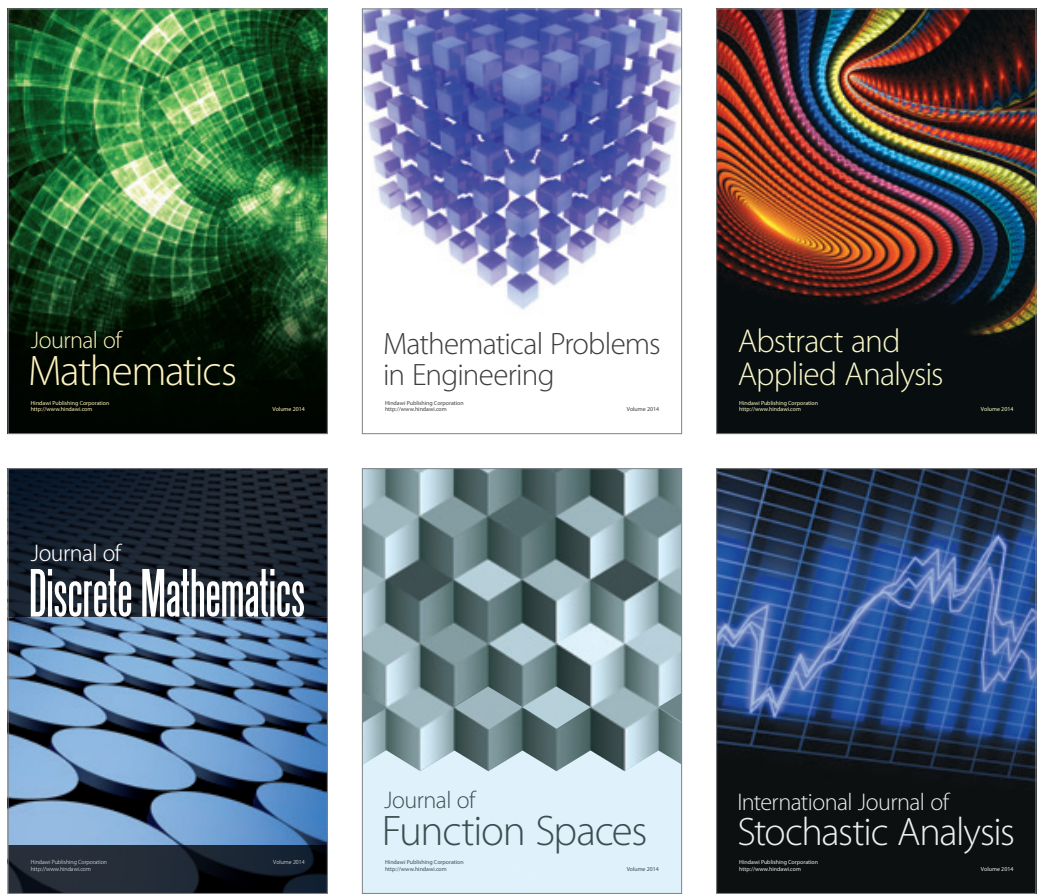

Journal of

Function Spaces

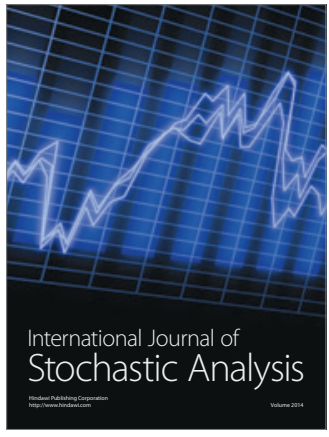

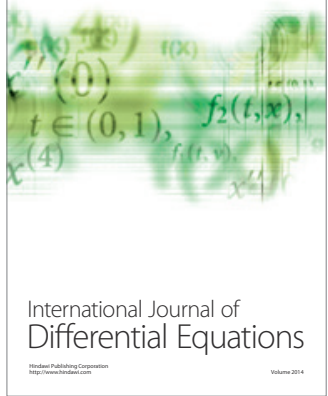
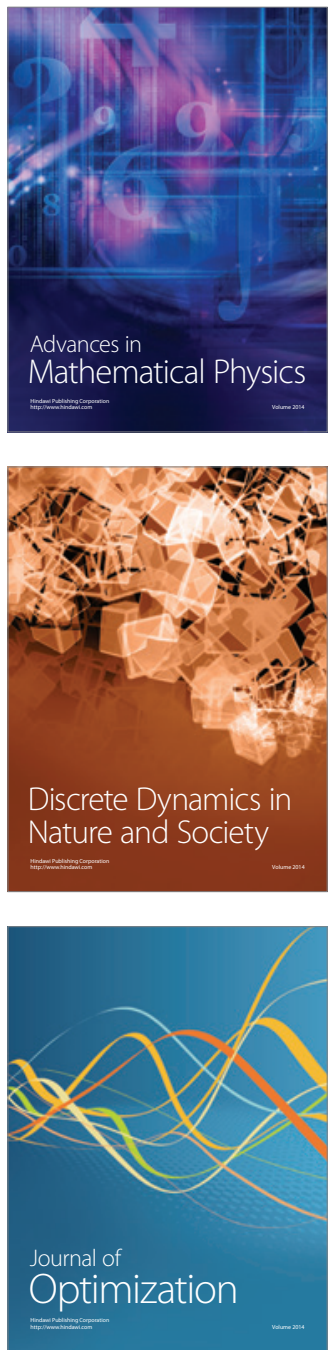